\title{
Analisis Teologis Tentang Tujuan Pendidikan Agama Kristen (PAK) dalam Matius 28:19-20
}

\author{
Rinaldus Tanduklangi \\ Institut Agama Kristen Negeri Toraja \\ renaldustanduk@gmail.com
}

\begin{abstract}
The Gospel of Matthew is a part of the new covenant the presents the great commission of the Jesus. The great commission is the command of the Lord Jesus to the disciples and to all believers in all ages. The great commission becomes the foundation in carrying out educational actions for the world in which Jesus has provided instructions, methods and ways of implementing them. The great commission becomes the foundation of education especially Christian religious education. This paper aims to analyze theologically the objectives of Christian religious education based on Matthew 28: 19-20. In an effort to trace the intention used qualitative-descriptive research methods. The results obtained that the purpose of PAK based on Matthew 28: 19-20's exposure is to make disciples of all nations, baptize and teach them to do all the commands of the Jesus.
\end{abstract}

Keywords: Great Commission; Christian education ; The purpose of Christian education

Abstrak: Injl Matius merupakan salah satu bagian kitab perjanjian baru yang menyajikan amanat agung Tuhan Yesus. Amanat agung ialah perintah Tuhan Yesus bagi para murid dan kepada semua orang percaya di segala zaman. Amanat agung menjadi landasan dalam melaksanakan tindakan pendidikan bagi dunia yang di dalamnya Yesus telah memberikan petunjuk, metode dan cara pelaksanaannya. Amanat agung menjadi landasan pendidikan khususnya pendidikan agama Kristen (PAK). Tulisan ini bertujuan untuk menganalasis secara teologis tujuan pendidikan agama kristen (PAK) berdasarkan Matius 28:19-20. Dalam upaya menelusuri maksud tersebut digunakan metode penelitian kualitatif-deskriptif. Hasil yang diperoleh bahwa tujuan PAK berdasarkan paparan Matius 28:19-20 ialah memuridkan segala bangsa, membaptis dan mengajar mereka melakukan segala perintah Tuhan Yesus.

Kata kunci: Amanat Agung; Pendidikan Agama Kristen; Tujuan pendidikan Agama Kristen.

\begin{tabular}{llll}
\hline Article History : & Received: 05-06-2020 & Revised: 26-06-2020 & Accepted: 26-06-2020
\end{tabular}

\section{Pendahuluan}

Pendidikan merupakan kontrak hidup manusia sebab sepanjang hidup manusia sejak dari kandungan hingga akhir hayatnya pendidikan terus berlangsung baik secara formal maupun nonformal. Pendidikan adalah proses edukasi untuk memanusiakan manusia pada tingkat yang lebih baik, lebih maju dan lebih bernilai serta lebih beradab. Selain itu, secara kodrati pula manusia diberi kemampuan berpikir sebagai penggerak untuk mau merubah, memperbaiki, memajukan serta meningkatkan taraf hidupnya dan 
semuanya itu hanya dapat diperoleh melalui pendidikan. Jadi pendidikan adalah bagian integral dalam hidup manusia.

Pendidikan merupakan salah satu perhatian utama dalam Alkitab. Oleh karena di dalam Alkitab terdapat proses edukasi yang diperankan oleh pendidik dan peserta didik. Peran tersebut terjadi di antara Allah dan umat-Nya. Alkitab memberi kesaksian bahwa Allah adalah pendidik yang tiada taranya (Ayb. 36:22) dan tidak ada yang dapat mengajari-Nya (Ayb. 21:22; Yes. 40:14), Dia mengajarkan pengetahuan kepada manusia (Mzm. 94:10). ${ }^{1}$ Pengajaran Allah kepada manusia, terjadi sepanjang sejarah manusia yang dapat dilihat dari berbagai peristiwa. Di antaranya Allah mengajar Adam dan Hawa di Taman Eden (Kej.1-2), Allah mengajar generasi setelah Adam dan Hawa yaitu Kain, Habel dan keturunan Adam lainnya (Kej. 5:22-24), Allah memberikan pendidikan dengan membuat perjanjian dengan Nuh dan keturunannya, Allah mengajar Abraham (Kej. 12:22), Allah mengajar umat Israel sejak dari Mesir dan dalam perjalanan menuju kanaan. ${ }^{2}$ Dalam upaya pendidikan yang diberikan Allah tidak hanya bertindak sebagai pendidik melainkan juga perencana dan pelaksana pendidikan. Jadi pendidikan adalah proses yang telah dimulai sejak penciptaan dunia dan terus berlangsung dalam sejarah keberadaan manusia.

Begitu pentingnya pendidikan banyak diutarakan di dalam Alkitab, bahkan menjadi sarana utama dalam mengenalkan setiap ketetapan dan maksud-maksud Allah. Tuhan Yesus sendiri ketika Ia berada di dunia ini, pendidikan merupakan bagian yang penting dalam setiap pelayanan-Nya. Hal tersebut nampak dalam setiap kegiatan Tuhan Yesus tindakan pendidikan melalui pengajaran paling banyak dilakukan puncaknya dijadikan sebagai mandat bagi setiap pengikut-Nya untuk meneruskan segala karya-Nya. Hal tersebut dinyatakan melalui perintah agung bagi para murid-Nya, "... Pergilah jadikanlah semua bangsa murid-Ku dan baptislah mereka dalam nama Bapa, dan Anak dan Roh Kudus dan ajarlah mereka melakukan segala sesuatu yang telah Kuperintahkan kepadamu dan ketahuilah Aku menyertai kamu senantiasa sampai kepada akhir zaman" (Mat. 28:19-20). Mandat ini dikenal sebagai amanat agung Tuhan Yesus. Amanat agung adalah panggilan pemberitaan Firman Tuhan yang memiliki nilai dan berlaku pada setiap zaman karena itu, panggilan ini bukan hanya diberikan oleh Tuhan Yesus namun para pengikut-Nya pun meneladani hal yang sama. ${ }^{3}$ Amanat yang tidak hanya berlaku dan diperuntukkkan bagi para murid melainkan kepada semua orang percaya tak terkecuali guru sebagai agen utama dalam dunia pendidikan turut andil dalam amanat tersebut. Amanat agung menjadi dasar bagi guru dalam melakukan tindakan pendidikan bagi dunia yang di dalamnya Yesus telah memberikan metode dan cara pelaksanaannya sehingga amanat ini menjadi pusat bagi pelaksanaan pendidikan. Bertolak dari pemahaman

\footnotetext{
${ }^{1}$ Harianto. Pendidikan Agama Kristen dalam Alkitab dan Dunia Pendidikan Masa Kini (Yogyakarta: ANDI, 2012), 3

2 Ibid. 4

${ }^{3}$ Yusak B. Hermawan, Beritakanlah Firman Tuhan (Yogyakarta: Andi,2010), 5
} 
demikian, kemudian penulis hendak menelusuri tujuan pendidikan agama kristen ditinjau dari sudut pandang amanat agung pada Injil Matius 28:19-20.

\section{Metode Penelitian}

Tulisan ini menggunakan penelitian kualitatif. Penelitian kualitatif merupakan penelitian yang bersifat deskriptif dengan analisis data yang lebih menekankan proses dan pemaknaan. Dalam upaya merampungkan data dan informasi pada tulisan ini penulis menggunakan metode library research (penelitian kepustakaan). Library research dilakukan dengan mencari dan meneliti informasi dari buku-buku dan dokumen terkait. Dalam mengumpulkan informasi, penulis melakukan beberapa tahapan yakni; Pertama. Menyajikan beberapa pengertian tentang PAK, Kedua. Menelusuri dan menyajikan tujuan PAK menurut para ahli. Ketiga. menyajikan tujuan PAK berdasarkan Injil Matius 28:19-20 melalui. Keempat. Menarik kesimpulan.

\section{Pembahasan}

\section{Definisi PAK}

Pendidikan agama Kristen (PAK) bertitik tolak dari amanat agung Tuhan Yesus yang terdapat dalam kitab Matius 28:19-20. Penyelenggarannya merupakan upaya pendewasaan pada murid yang dilakukan melalui baptisan dan ajaran. PAK adalah proses pengajaran dan pembelajaran yang berdasarkan Alkitab, berpusat pada Kristus, dan bergantung kepada Roh Kudus yang membimbing setiap pribadi pada semua tingkat pertumbuhan melalui pengajaran masa kini ke arah pengenalan dan pengalaman rencana dan kehendak Allah melalui Kristus dalam setiap aspek kehidupan, dan melengkapi mereka bagi pelayanan yang efektif, yang berpusat pada Kristus sang guru Agung dan perintah yang mendewasakan pada murid".4 PAK merupakan usaha untuk mengembangkan kemampuan dan wawasan nara didik tentang konsepsi kerajaan Allah supaya mereka memiliki pegangan dalam memasuki dunia nyata. 5 Dengan adanya pengajaran PAK, wawasan peserta didik dikembangkan supaya ia mengenal Allah dan karya-Nya serta memiliki pegangan yang jelas dalam hidupnya.

Pada konsultasi pendidikan kristen tahun 1986 di Salatiga dikemukakan bahwa PAK adalah usaha untuk membantu peserta didik bertumbuh dan berkembang mencapai kepribadian yang utuh, sebagai cerminan manusia sebagai gambar Allah yang memiliki kasih dan ketaatan kepada Tuhan, kecerdasan, keterampilan, budi pekerti luhur serta tanggung jawab untuk berperan dalam pembangunan masyarakat dan bangsa. ${ }^{6} \mathrm{PAK}$ ialah kegiatan mengajar yang membimbing peserta didik mengenal rencana dan kehendak

4 Paulus Lilik Kristianto, 4.

${ }^{5}$ Weinata Sairin. Indentitas dan Ciri Khas Pendidikan Kristen di Indonesia Antara Konseptual dan Operasional (Jakarta: BPK. Gunung Mulia, 2003), 221.

6 Ibid. 223 
Allah dalam hidupnya supaya menjadi pelayan yang efektif dan menjadi murid yang dewasa. Kegiatan dalam PAK dilakukan secara sadar dan terencana dengan proses pembelajaran yang melibatkan peserta didik. Sebagaimana Harianto berpendapat PAK adalah usaha sadar dan terencana untuk meletakkan dasar Yesus Kristus (2 Kor. 3:13) dalam pertumbuhan iman Kristus dengan cara mewujudkan suasana belajar dan proses pembelajaran agar peserta didik secara aktif mengembangkan potensinya untuk memiliki kekuatan spiritual keagamaan, yaitu melandaskan, pengendalian diri, kepribadian, kecerdasan, akhlak mulia serta keterampilan yang diperlukan dirinya dan masyarakat. ${ }^{7}$

Dari uraian di atas, disimpulkan bahwa PAK ialah usaha sadar dan terencana untuk memberikan pengetahuan, pengajaran dan bimbingan berdasarkan ajaran dan nilai-nilai kristiani kepada setiap peserta didik supaya aktif mengembangkan seluruh potensinya dan memiliki kekuatan spritual keagamaan dengan kecerdasan, keterampilan serta akhlak mulia yang berguna bagi dirinya dan masyarakat. PAK adalah bantuan yang diberikan kepada peserta didik dalam bertumbuh dan berkembang menjadi pribadi yang mencerminkan gambar dan rupa Allah.

\section{Tujuan PAK menurut Para Ahli}

Dalam buku Pendidikan Agama Kristen Homrighousen berkata Pendidikan Agama Kristen (PAK) berpangkal pada persekutuan umat Tuhan, PAK bermula sejak terpanggilnya Abraham menjadi nenek moyang umat pilihan Tuhan bahkan bertumpu pada Allah sendiri sebagai pendidik bagi umat-Nya. ${ }^{8}$ Lebih lanjut pada buku yang lain dijelaskan PAK pada dasarnya bertujuan untuk memimpin murid selangkah demi selangkah kepada pengenalan peristiwa-peristiwa yang terdapat di dalam Alkitab dan pengajaran-pengajaran yang diberikan olehNya, membimbing murid dalam cara menggunakan kebenaran-kebenaran asasi Alkitab itu untuk keselamatan seluruh hidupnya dan mendorong dia mempraktekkan azas-azas dari Alkitab itu supaya membina suatu perangai Kristen yang kukuh serta menyakinkan supaya mengakui bahwa kebenaran-kebenaran dan azas iman itu menunjukkan jalan untuk memecahkan masalahmasalah kesusilaan, sosial dan politik di dunia ini. ${ }^{9}$ Sementara itu bagi Groome, tujuan PAK ialah untuk memampukan orang-orang hidup sebagai orang Kristen yakni hidup sesuai dengan iman Kristen. ${ }^{10}$ Esensi dari iman ialah keyakinan, hubungan yang penuh kepercayaan dan kehidupan agape yang hidup. Melalui pembelajaran PAK, setiap orang akan dibimbing dengan pengajaran-pengajaran yang bersumber dari Alkitab dan

\footnotetext{
${ }^{7}$ Harianto, Pendidikan Agama Kristen dalam Alkitab dan Dunia Pendidikan Masa Kini, 52

8 E.G.Homrighausen, Pendidikan Agama Kristen (Jakarta: BPK Gunung Mulia, 1985), 112

9 E.G.Homrighausen dan I. H. Enklaar, Pendidikan Agama Kristen (Jakarta: BPK Gunung Mulia, 2005), 95

10 Thomas H. Groome, Christian Religious Education: Pendidikan Agama Kristen (Jakarta: BPK. Gunung Mulia, 2015), 48
} 
selanjutnya dimampukan untuk mempercayai, menyakini dan mempraktekkan pengajaran tersebut agar ia hidup dengan iman Kristiani yang benar.

Orientasi dalam PAK ialah membimbing setiap individu mengenal tujuan dan rencana Allah dalam Kristus supaya semakin diperlengkapi dalam kehidupan dan kepelayanannya. Hal tersebut senada dengan ungkapan Wenner, tujuan PAK ialah membimbing individu-individu pada semua tingkat perkembangannya dengan cara pendidikan kontemporer menuju pengenalan serta pengalaman akan tujuan serta rencana Allah dalam Kristus melalui setiap aspek kehidupan dan juga untuk memperlengkapi mereka demi pelayanan yang efektif.11 Lebih rinci Sariaman Sitanggang mengemukakan tujuan PAK adalah memperkenalkan Allah Bapa, Anak dan Roh Kudus dan karya-karya-Nya agar iman dan kepercayaan peserta didik bertumbuh dan meneladani Allah Tritunggal dalam hidupnya, menanamkan pemahaman tentang Allah dan karya-Nya kepada peserta didik sehingga mampu memahami dan menghayatinya. ${ }^{12}$ Dalam penjelasan ini hal yang ingin dicapai dalam pembelajaran PAK tak lain ialah memperkenalkan Allah Tritunggal dan menanamkan pemahaman akan Allah kepada peserta didik sehingga mampu memberi penghayatan terhadap setiap karya Allah. PAK pada dasarnya bertujuan untuk menanamkan nilai-nilai Kristiani dalam kehidupan sosial dan pribadi peserta didik agar ia tumbuh mengenal Allah Tritunggal berserta karya-Nya.

\section{Tujuan PAK menurut Injil Matius 28:19-20}

Injil Matius 28:19-20 merupakan salah satu perikop yang disebut sebagai Amanat agung. Amanat agung yang disampaikan oleh Tuhan Yesus kepada para murid-Nya pasca kebangkitan-Nya. Amanat agung yang merupakan perintah tunggal Tuhan Yesus setelah Dia bangkit dari kematian-Nya. Peters dalam buku A Biblical Theology Of Missions, menegaskan:

Amanat agung merupakan suatu penyajian terakhir yang logis dan merupakan ekspresi alami dari karakter Allah, seperti diwahyukan dalam Alkitab. Amanat agung merupakan ekspresi dari maksud serta tujuan misioner Allah, ekspresi dari kehidupan, teologi dan karya keselamatan Kristus. Amanat agung merupakan Ekspresi dari sifat dan pekerjaan Roh Kudus dan ekspresi dari hakikat dan rencana dari gereja Yesus Kristus. Amanat agung membentuk kesatuan organik serta merupakan bagian tak terpisahkan dari penyataan itu sendiri. ${ }^{13}$

Selain dalam Injil Matius, Amanat agung terdapat juga dalam empat bagian Alkitab lainnya yakni Markus 16:15-18, Lukas 24:44-49, Yohanes 20:19-23; 21:15-29, dan Kisah

11 Daniel Nuhamara, Pembimbing PAK. (Bandung: Jurnal Info Media, 2009), 31.

${ }^{12}$ Sariaman Sitanggang, Bagaimana Menyusun KTSP dan Perencanaan Pembelajaran Pendidikan Agama Kristen, (Jakarta: Engkratela Putra Jaya, 2008), 58.

${ }^{13}$ George W. Peters, A Biblical Theology of Missions (Malang: Gandum Mas, 2006), 212. 
Para Rasul 1:6-8. Bagian-bagian Alkitab ini ditulis oleh empat orang penulis dalam visi dan segi yang berbeda untuk saling melengkapi. ${ }^{14}$ Kata Peters, Injil Matius menekankan otoritas, tujuan yang lengkap dan lingkup waktu yang diperluas dari karya tersebut. Injil Markus menekankan keadaan yang mendesak, metode dan lingkup geografis karya tersebut. Injil Lukas menekankan Amanat keuniversalan karya tersebut dan Injil Yohanes menekankan sifat dan peralatan rohani dari karya tersebut". ${ }^{15}$ Hesselgrave menambahkan "Injil Markus lebih menekankan khotbah dan proklamasi sedangkan Injil Lukas lebih menekankan proklamasi dan kesaksian". ${ }^{16}$ Jadi masing-masing penulis Injil, menyajikan Amanat agung menurut sudut pandangnya dengan penekanan yang unik namun secara bersama-sama memberikan penyajian yang utuh dan saling melengkapi.

Pada Injil Matius, amanat agung terdiri dari tiga bagian penting yakni pemberian otoritas dari Yesus, mandat Yesus yang berkesinambungan, dan pemberian janji penyertaan oleh Yesus. ${ }^{17}$ Pemberian otoritas dari Yesus dinyatakan melalui perkataanNya ketika Ia telah bangkit 'kepada-Ku telah diberikan segala kuasa di bumi dan di sorga'. Pengucapan otoritas tersebut mengingatkan pada Daniel 7:13-14 dan juga perkataan-Nya di hadapan Mahkamah (Mat. 26:64) sehingga tidak ada lagi wilayah, bangsa, atau budaya yang tidak berada dalam daerah kekuasaan dan otoritas-Nya. Dengan otoritas dan kedaulatan yang tinggi Yesus memberikan mandat yang berkesinambungan bagi para murid-Nya. Mandat tersebut berupa empat kata kerja present tense yaitu "pergilah ( ( $\delta \iota \delta \alpha ́ \sigma \kappa o v \tau \varepsilon \varsigma)$. Setelah selesai memberikan perintah kepada murid-Nya, Yesus menambahkan sebuah janji penyertaan bahwa Ia tidak akan meninggalkan para muridNya melainkan akan selalu menyertai sampai akhir zaman. Janji itu berlaku untuk setiap murid di setiap zaman dan tempat. Janji yang bukan sekedar menyertai saja melainkan membantu dan memihak para murid-Nya. ${ }^{18}$

Amanat agung merupakan mandat sekaligus menjadi landasan dalam melaksanakan pendidikan. Melalui amanat agung, Tuhan Yesus nyata telah menandaskan tugas pendidikan bagi guru lengkap dengan tujuan-tujuan yang telah ditetapkan-Nya. Tujuan dalam amanat agung menjadi orientasi bagi pendidikan agama kristen (PAK). Dengan kata lain tujuan dari amanat agung menjadi muara sekaligus menjadi tujuan Pendidikan Agama Kristen (PAK). Berkenaan dengan itu, untuk mengetahui tujuan PAK berdasarkan paparan Matius 28:19-20, berikut ini penulis akan menguraikan beberapa kata kerja yang terkandung di dalamnya sebagai berikut:

\footnotetext{
14 Yakob Tomatala, Penginjilan Masa Kini 1 (Malang: Gandum Mas, 2004), 25.

15 Peters, A Biblical Theology of Missions, 213.

16 David J. Hesselgrave, Communicating Christ Cross-Culturally (Malang: SAAT, 2005), 77.

${ }^{17}$ John R. W. Stott, Johannes Verkuyl, dkk., Misi Menurut Perspektif Alkitab (Jakarta: Yayasan Komunikasi Bina Bangsa, 2007), 73.

${ }^{18}$ Hasan Sutanto, Perjanjian Baru Interlinear Yunani-Indonesia dan Konkordansi Perjanjian Baru Jilid II (Jakarta: Lembaga Alkitab Indonesia, 2006), 661.
} 


\section{Pergilah}

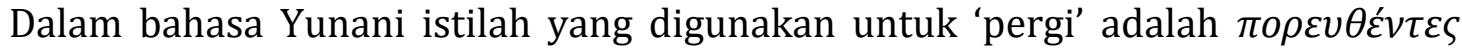
yang merupakan kata kerja pembantu. $\pi о \rho \varepsilon v \theta \varepsilon ́ v \tau \varepsilon \varsigma$ (poreuthentes) diartikan sebagai go (pergi), proceed (lanjutkan), dan travel (melakukan perjalanan). ${ }^{19} \pi o \rho \varepsilon v \theta \varepsilon ́ v \tau \varepsilon \varsigma$ (poreuthentes) yang berarti berangkat, pergi, melintasi batas-batas sosial, rasial, budaya dan geografis. ${ }^{20}$ Dalam Perjanjian Baru Interlinear Yunani-Indonesia..., kata pergi diterjemahkan dengan istilah poreuo yang berarti "pergi, berangkat, berpergian, berjalan,

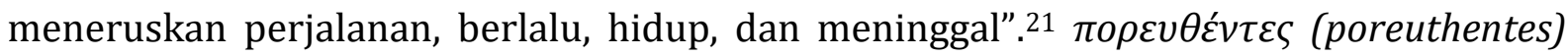
adalah bentuk participle maskulin jamak yang berfungsi sebagai subyek aorist pertama dari kata poreumai, sebuah kata kerja deponen (kata kerja pasif) yang mempunyai arti lewat dari satu tempat ke tempat lain, pergi. ${ }^{22}$ Kata ini mengalami perubahan bentuk kata sesuai dengan subyek dari kata perintah yang ada di belakangnya secara langsung. ${ }^{23}$

Poreuthentes dalam bentuk aorist parcticiple (imperative) memberikan pengertian bahwa para murid harus terus-menerus pergi untuk melakukan tugas yang sudah diperintahkan oleh Tuhan Yesus dan selagi para murid baru memulai 'pergi' berjalan atau sedang dalam perjalanan melakukan tugas kepada mereka diberi kuasa. ${ }^{24}$ Kata 'pergilah' dalam bentuk partisif diikuti dengan bentuk imperaktif yang digunakan untuk memerintahkan kepada para murid untuk memuridkan, membaptis dan mengajar. ${ }^{25}$ Kata 'pergilah' mendefenisikan bahwa Amanat agung adalah perintah yang harus dilakukan dalam setiap situasi, di mana saja berada (sementara kamu pergi), di komunitas hidup sehari-hari (melanjutkan), dan terlibat dengan proyek misi baik sebagai misionaris maupun sebagai pengutus. Pada Bible Works penjelasan dari poreuthentes diartikan sebagai 'as a euphemism go to one's death'.26 Penjelasan ini mempunyai arti setiap murid dipanggil untuk menjadi radikal dalam arti taat sampai mati seperti yang dilakukan oleh Tuhan Yesus. Frasa 'pergilah' merupakan istilah yang mengandung makna yang sangat dalam, bukan hanya sebatas pengutusan melainkan sebuah panggilan iman untuk terlibat mengambil bagian dalam menjalankan misi Tuhan Yesus yakni menjadikan seluruh bangsa menjadi murid-Nya. Panggilan ini didasarkan pada ketetapan Allah sendiri melalui Yesus Kristus dan bertujuan untuk melanjutkan karya penyelamatan Allah melalui pemberitaan Injil ke seluruh bangsa.

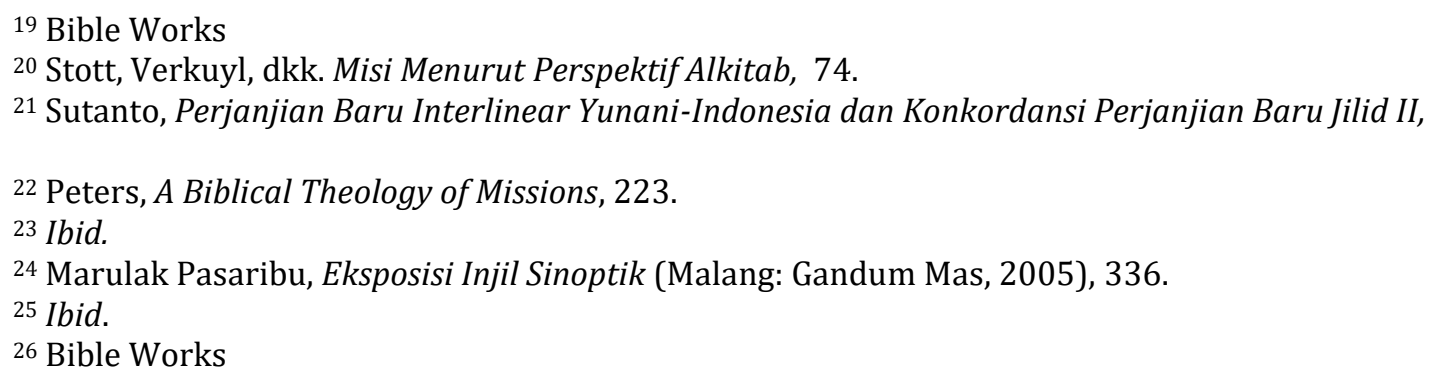




\section{Jadikanlah}

Dalam bahasa Yunani istilah 'jadikanlah murid' diterjemahkan menjadi $\mu \alpha \theta \eta \tau \varepsilon v ́ \sigma \alpha \tau \varepsilon . \mu \alpha \theta \eta \tau \varepsilon v ́ \sigma \alpha \tau \varepsilon$ dengan bentuk imperative menunjukkan suatu perintah yang mendorong seseorang untuk melakukan sesuatu, sedangkan penggunaan tense aorist menunjukkan sesuatu pekerjaan yang baru dimulai dan pekerjaan itu harus terusmenerus dilakukan. ${ }^{27} \mu \alpha \theta \eta \tau \varepsilon v ́ \sigma \alpha \tau \varepsilon$ (Matheteusale) berbentuk orang kedua jamak, perintah aorist aktif pertama dari $\mu \alpha \theta \eta \tau \varepsilon u ́ \omega$ (matheteuo) dan mempunyai kata dasar mathetes (murid). ${ }^{28}$ Bentuk kata kerja hanya muncul empat kali dalam perjanjian baru (Mat. 13:52; 27:57; 28:29, Kis. 14:21). ${ }^{29}$ Kata ini adalah perintah, baik dilihat dari bentuk maupun artinya dan satu-satunya bentuk perintah verbal dalam ayat 19-20. Dalam terjemahan baru LAI, ditemukan pula bahwa keempat kata kerja dalam ayat ini semuanya memakai bentuk imperatif (perintah) tetapi dalam kalimat Yunani bentuk imperatif itu muncul hanya satu kali yakni "jadikanlah murid-Ku" dan ketiga kata kerja lainnya memakai bentuk participium (poreuthentes, baptizontes, didaskontes). Oleh sebab itu, memuridkan atau menjadikan murid merupakan kata kerja pokok dalam Amanat agung sedangkan kata kerja lainnya yang berbentuk participle merupakan cara dan metode untuk melaksanakan Amanat tersebut. 30

Jadikanlah murid-Ku merupakan pusat dan tujuan utama dalam kedua ayat ini (ayat 19-20). Istilah 'murid' merupakan sebutan yang paling populer bagi umat percaya mula-mula. Murid adalah orang yang percaya kepada Yesus Kristus dan mengungkapkan imannya dengan memberi diri dibaptis sebagai tanda pertobatan. Murid senantiasa berada dalam persekutuan orang percaya agar dapat mempelajari kebenaran-kebenaran iman kemudian dapat keluar dan memenangkan orang lain serta mengajarnya. ${ }^{31}$ Seorang murid lebih dari sekadar seorang petobat. Seorang murid mengikat dirinya dengan seorang guru, menjadi sama dengan dia, belajar dari dia, hidup dengan dia dan belajar bukan hanya mendengar melainkan juga melihat dan melakukan. ${ }^{32}$

Jadikanlah murid-Ku adalah perintah yang telah dimandatkan dan harus disampaikan kepada seluruh bangsa. Dalam bahasa Yunani istilah 'seluruh bangsa' diterjemahkan dengan kata 'ta ethne'. Kata ini menunjukkan bahwa pelayanan berorientasi kepada semua bangsa yakni kepada siapa saja para murid harus mengabarkan injil dan apapun konteks dari pendengar, para murid diperintahkan untuk menjadikan mereka murid-murid Yesus. ${ }^{33}$ Selagi para murid pergi atau sedang dalam perjalanan dilimpahkan kuasa untuk "menjadikan murid", mengadakan transformasi

27 Pasaribu, Eksposisi Injil Sinoptik, 336.

28 Peters, A Biblical Theology of Missions, 223.

${ }^{29}$ Arliyanus Larosa, Memuridkan Dunia: Melaksanakan Amanat Agung (Bandung: Yayasan Kalam Hidup, 2005), 22.

30 J.T. Nielsen. Tafsiran Alkitab Kitab Injil Matius 23-28 (Jakarta: BPK. Gunung Mulia, 2012), 197.

31 Warren W. Wiersbe. Loyal Di Dalam Kristus (Bandung: Yayasan Kalam Hidup, 2012), 325.

32 Ibid.

33 Pasaribu, Eksposisi Injil Sinoptik, 337. 
dalam kehidupan orang-orang berdosa yang mendengarkan mereka. Mereka yang ditransformasikan ialah ta ethne, segala suku bangsa dengan latar belakang budaya yang berbeda-beda.

Perintah 'jadikanlah murid-Ku' adalah tujuan yang akan dicapai dalam amanat agung. Menjadikan bangsa menjadi murid adalah misi Tuhan Yesus yang harus menjadi sasaran dalam melaksanakan pengajaran (pendidikan). Maka dari itu, dalam mengajar seorang guru bukan hanya sekadar menyampai berita injil namun sungguh-sungguh menyaksikan kebenaran kepada peserta didiknya dengan pimpinan Roh Kudus dan setelah peserta didiknya menerima dan percaya kepada Yesus sebagai Tuhan dan Juruselamatnya, guru tetap terlibat untuk mendampinginya bertumbuh. Sebab tujuan dari pendidikan ialah memenuhi amanat agung bukan hanya sampai pada 'memberitakan Injil' melainkan menjadikannya 'murid' Yesus.

\section{Baptislah}

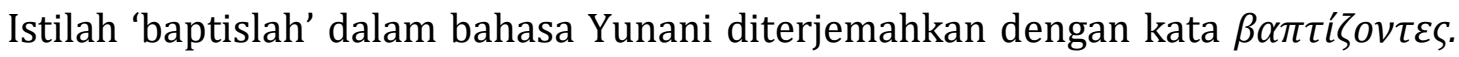
Kata $\beta \alpha \pi \tau i ́ \zeta o v \tau \varepsilon \varsigma$ berbentuk present partisive (imperative) memiliki arti kegiatan membaptis tidak lagi dibatasi oleh waktu melainkan suatu tindakan yang harus terusmenerus terjadi (a continus action). ${ }^{34}$ Kata Culver yang dikutip oleh Peters, sebenarnya kata baptizontes tidak berbentuk perintah namun karena hubungan dan kedudukannya dengan kata kerja yang mempengaruhinya, maka kata ini mempunyai kedudukan untuk menyampaikan gagasan perintah. ${ }^{35}$ Dalam Perjanjian Baru Interlinear..., baptisan diterjemahkan dengan kata 'baptizo' yang berarti 'membasuh (dalam penyucian ritual orang Yahudi); membaptis'. ${ }^{36}$ Mounce, menambahkan nuansa baptisan sebagai tindakan yang mencerminkan dedikasi. ${ }^{37}$ Selanjutnya Henry memberikan penjelasan:

Baptisan sebagai sebuah sakramen merupakan sebuah sumpah; super sacramentum dicere, yang artinya mengatakan di bawah sumpah. Baptisan adalah sebuah sumpah untuk meninggalkan sesuatu, yang melaluinya kita melepaskan dunia dan kedagingan sebagai musuh Allah dalam menduduki tahta hati kita. Baptisan adalah sumpah setia yang melaluinya kita berserah dan memberikan diri kita menjadi milik Allah yakni segenap jiwa, raga dan roh untuk dikuasai oleh kehendak-Nya dan dibuat bahagia dalam anugerah-Nya. Kita menjadi umat-Nya sehingga kita berbakti kepada-Nya. Oleh karena itulah baptisan diterapkan pada

${ }^{34}$ Ibid.

35 Peters, A Biblical Theology of Missions, 223.

36 Sutanto, Perjanjian Baru Interlinear Yunani-Indonesia dan Konkordansi Perjanjian Baru Jilid II, 141.

37 William D. Mounce, The Analitical Lexicon to The Greek New Testament (Grand Rapids Michigan: Zondervan, 1999), 112. 
pribadi seseorang karena yang didedikasikan kepada Allah adalah seorang manusia. $^{38}$

Baptisan adalah fase baru yang dimasuki oleh seseorang setelah percaya dan menerima Yesus sebagai Tuhan dan Juruselamatnya. Dengan menerima baptisan seseorang menyatakan pertobatan dan kepercayaan yang sungguh kepada Yesus. Karena itu setelah menerima baptisan wajib untuk menjadikan perintah Kristus sebagai pengangan, memperhatikan apa yang telah diperintahkan Kristus, memperhatikan segala sesuatu yang Dia perintahkan tanpa pengecualian yaitu seluruh kewajiban moral dan segala tata aturan yang telah dilembagakan atau ditetapkan, membatasi diri hanya pada perintah-perintah Kristus dan mempelajari dan mengenal kewajiban menurut hukum Kristus. ${ }^{39}$ Lewat baptisan seseorang mengikat dirinya di bawah sumpah dengan Allah dan hanya menaruh kepercayaan kepada Allah saja.

Dalam hal baptisan, Tuhan Yesus telah memberikan contoh dalam hidup-Nya sebagai manusia membaptiskan diri-Nya sebelum memulai pelayanan-Nya sekalipun bukanlah manusia berdosa namun Ia dibaptiskan karena menggenapkan seluruh kehendak Allah. Yesus tidak hanya dibaptis oleh Yohanes pembaptis (Mat. 3:13-37) melainkan juga secara aktif membaptis orang lain baik yang dilakukan sendiri maupun oleh para murid-Nya. Maka dari itu, Ia kemudian mengamanatkan pembaptisan ini kepada para murid-Nya yang dikaitkan dengan Allah Tritunggal. Jadi baptisan bukanlah perintah atau persyaratan yang dibuat-buat oleh manusia melainkan perintah dari Tuhan Yesus sendiri. Baptisan merupakan pengukuhan tentang kesiapan dan kesetiaan dalam mengiring Yesus.

\section{Ajarlah}

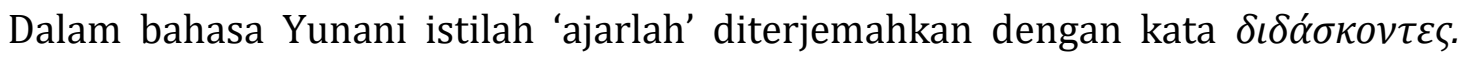
Kata $\delta \iota \delta \alpha ́ \sigma \kappa o v \tau \varepsilon \varsigma$ ini sejajar dengan kata $\beta \alpha \pi \tau i ́ \zeta o v \tau \varepsilon \varsigma$ bentuknya sama yaitu present partisive (imperative) yang berarti suatu pekerjaan yang terus-menerus dilakukan ( $a$

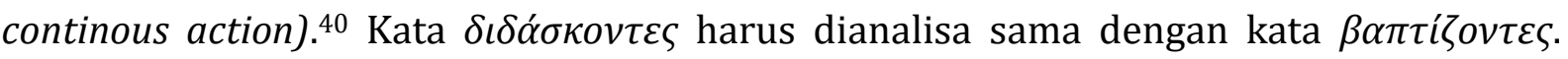
Artinya aktivitas mengajar dikaitkan dengan aktivitas membaptis. ${ }^{41}$ Dalam Perjanjian Baru Interlinear Yunani..., kata 'mengajar' dan 'mengajarkan' diterjemahkan 'didasko', sedangkan kata 'perbuatan mengajar' dan 'ajaran' diterjemahkan 'didakhe, dan didaskalia'. ${ }^{2}$

\footnotetext{
${ }^{38}$ Matthew Henry, Tafsiran Matthew Henry: Injil Matius 15-28, terj. Herdian Apriliani dkk. (Surabaya: Momentum, 2008), 1573.

39 Ibid. 1575

${ }^{40}$ Pasaribu, Eksposisi Injil Sinoptik, 338.

41 Peters, A Biblical Theology of Missions, 224.

42 Sutanto, Perjanjian Baru Interlinear Yunani-Indonesia dan Konkordansi Perjanjian Baru Jilid II 204.
} 
Baik Perjanjian Lama maupun Perjanjian Baru memberikan beberapa istilah terkait kata 'mengajar'. Dalam Perjanjian Lama ada dua istilah yang berarti mengajar yaitu 'lamad' dan 'yarah'. Kata 'lamad' dipakai 85 kali dalam kitab Perjanjian Lama dan pertama kali digunakan dalam Ulangan 4:1 yang berhubungan dengan khotbah Musa di hadapan Allah tentang pengajaran yang telah diberikan kepadanya dan dalam Ulangan 5:1 yang berhubungan dengan mengajar hukum Tuhan. Sedangkan kata'yarah' digunakan 80 kali dalam Perjanjian Lama dan tidak hanya berarti mengajar tetapi juga melempar dan menembak. Ketika ia berarti mengajar maka ia berhubungan dengan tindakan menyampaikan pengajaran. ${ }^{43}$ Lain halnya dalam kitab Perjanjian Baru kata mengajar diterjemahkan dalam beberapa istilah seperti euangelizo, kerusso, parrhesiazomai, didasko, katecho dan paideou. Istilah tersebut masing-masing mendefenisikan kegiatan mengajar sebagai berikut:

Euangelizo hanya digunakan dalam hubungan membawa Injil atau memberitakan Injil di hadapan orang banyak ataupun secara pribadi (Luk. 1:19, 1 Tes. 3:6). Kerusso berarti mengajar dalam hubungan dengan memproklamasikan (Mat. 3:1, Mark. 1:45, Luk. 4:18, Rm. 2 :21). Parrhesiazomai berkaitan dengan mengajar dengan keberanian (Kis. 9:27). Didasko berarti mengajar dalam hubungan memberikan intruksi di hadapan hadirin (Mat. 4:23; 9:35, 1 Tim. 2:12). Katecheo berarti mengajar di hadapan pertemuan (1 Kor. 14:19). Paideou menyatakan tindakan mengajar yang berkaitan dengan membimbing disertai intruksi dan latihan (2 Tim. 2:25). ${ }^{44}$

Mengajar merupakan bagian terpenting dari amanat agung. Mengajar yang tidak semata - mata dimaksudkan untuk menanamkan perintah - perintah torah dan menaatinya melainkan taat kepada kehendak Allah sebagaimana yang diungkapkan dalam pelayanan dan pengajaran Yesus. Jhon Nolland menegaskan yang menjadi perintah 'ajarlah mereka melakukan segala sesuatu' ialah semua pengajaran Yesus di dalam Injil mengenai kisah penebusan yang berpusat pada Kristus, tentang cara kabar baik terbentang dan makna dari kisah tersebut. ${ }^{45} \mathrm{Hal}$ itu berarti dalam mengajar yang menjadi isi pengajaran ialah segala sesuatu yang dikerjakan dan diperintahkan oleh Tuhan Yesus dan dinyatakan di dalam Alkitab.

\section{Kesimpulan}

Pendidikan agama kristen bertitik tolak dan bermuara pada amanat agung Tuhan Yesus yang nyata telah mengamanatkan tugas pendidikan pada setiap pendidik atau

43 Yusak B. Hermawan, Beritakanlah Firman Tuhan, 11.

44 Ibid. 12.

45 Jonathan K. Dodson, Pemuridan yang berpusatkan Injil, (Wheaton: Anggota IKAPI, 2012), 36. 
pengajar. Amanat agung menjadi amanat pendidikan agama Kristen (PAK) sehingga tujuan dari amanat agung menjadi pula tujuan bagi pendidikan agama Kristen (PAK). Pendidikan agama Kristen (PAK) merupakan upaya untuk memenuhi tujuan amanat agung yakni menjadikan seluruh bangsa menjadi murid Kristus dan mengajar mereka melakukan segala perintah-perintah-Nya. Dengan demikian pula, maka pendidikan agama Kristen (PAK) bertujuan untuk memuridkan segala bangsa, membaptis dan mengajar mereka melakukan segala perintah Tuhan Yesus.

\section{Referensi}

Dodson, Jonathan K. 2012. Pemuridan Yang Berpusatkan Injil. Wheaton: Anggota IKAPI. GP, Harianto. 2012. Pendidikan Agama Kristen Dalam Alkitab \& Dunia Pendidikan Masa Kini. Yogyakarta: ANDI.

Groome, Thomas H. 2015. Christian Religious Education: Pendidikan Agama Kristen Jakarta: BPK. Gunung Mulia,

Henry, Matthew. 2008. diterjemahkan oleh Herdian Apriliani dkk. Tafsiran Matthew Henry: Injil Matius 15-28. Surabaya: Momentum.

Hermawan, Yusak B. 2010. Beritakanlah Firman Tuhan. Yogyakarta: ANDI.

Hesselgrave, David J. 2005. Communicating Christ Cross-Culturally. Malang: SAAT Homrighausen, E.G. 1985. Pendidikan Agama Kristen. Jakarta: BPK Gunung Mulia.

Homrighausen E.G.dan I. H. Enklaar. 2005. Pendidikan Agama Kristen. Jakarta: BPK Gunung Mulia

Kristanto, Paulus Lilik. 2008. Prinsip \& Praktik Pendidikan Agama Kristen. Yogyakarta: Andi.

Larosa, Arliyanus. 2005. Memuridkan Dunia: Melaksanakan Amanat agung. Bandung: Yayasan Kalam Hidup.

Mounce, William D. 1999. The Analitical Lexicon to The Greek New Testament. Grand Rapids Michigan: Zondervan.

Nuhamara, Daniel. 2009. Pembimbing PAK. Bandung: Jurnal Info Media Nielsen, J.T. 2012. Tafsiran Alkitab Kitab Injil Matius 23-28. Jakarta: BPK Gunung Mulia.

Pasaribu, Marulak. 2005. Eksposisi Injil Sinoptik. Malang: Gandum Mas.

Peters, George. W. 2006. A Biblical Theology of Missions. Malang: Gandum Mas.

Sairin, Weinata. 2003. Indentitas dan Ciri Khas Pendidikan Kristen di Indonesia Antara Konseptual dan Operasional, Jakarta: BPK. Gunung Mulia.

Sitanggang, Sariaman. 2008. Bagaimana Menyusun KTSP dan Perencanaan Pembelajaran Pendidikan Agama Kristen, Jakarta: Engkratela Putra Jaya

Stott, John R. W., Johannes Verkuyl, dkk.. 2007. Misi Menurut Perspektif Alkitab. Jakarta: Yayasan Komunikasi Bina Bangsa.

Sutanto, Hasan. 2006 Perjanjian Baru Interlinear Yunani - Indonesia dan Konkordansi Perjanjian Baru Jilid II. Jakarta: Lembaga Alkitab Indonesia.

Tomatala, Yakob. 2004. Penginjilan Masa Kini 1. Malang: Gandum Mas.

Warren, Rick. 2005. The Purpose Driven Church. Malang: Gandum Mas.

Wiersbe, Warren W. 2012. Loyal Di Dalam Kristus Bandung: Yayasan Kalam Hidup. 